1. Assistant Professor Dermatology, Dow International Medical College, Dow University Hospital (Ojha),

\section{Correspondence Address:}

Dr. Sadaf Ahmed Asim

Assistant Professor Dermatology, Dow International Medical College, Dow University Hospital (Ojha), doc.sadaf.ahmed@gmail.com

\section{Article received on:} 05/03/2015

Accepted for publication: 01/06/2015

Received after proof reading: 09/09/2015

\title{
COMMON BIRTH MARKS; \\ TO IDENTIFY THE FREQUENCY IN INFANTS PRESENTING TO OUT PATIENT OF TERTIARY CARE HOSPITAL
}

Dr. Sadaf Ahmed Asim', Dr. Humaira Maryum², Dr. ShaziaShukar-ud-din ${ }^{3}$, Dr. Waseem Jamalvi ${ }^{4}$, Dr. Muhammad Aurangzeb ${ }^{5}$

ABSTRACT...Objectives: To identify the frequency of common birthmarks presenting in outpatients department of dermatology until and to increase awareness among doctor about the common phenomena. Patients and Study Design: A cross sectional study. Setting: OPD of Dermatology department of Dow University Hospital. Period: January 2014 till October 2014. Methods:During a year, by using non-probability convenient sampling only 100 patients of both genders were enrolled in the study after ensuring inclusion, exclusion criteria. Complete history was recorded and a thorough general physical and cutaneous examination was performed. Information was collected on predesigned questionnaire after taking informed consent. Data Analysis was carried out on SPSS statistics software. Results: Out of 100 patients, $43 \%$ were males and $57 \%$ were females. In $69.6 \%$ patients, the birthmarks were noticed around time of delivery, $28.3 \%$ patients were noticed within 1 st year of life and $2.2 \%$ later in 5 year. Pigmented birthmarks were identified in $65.2 \%$ patients while $34.8 \%$ have vascular birthmarks.71.1\% had no changes in color during life span. While $37.8 \%$ had $1-3 \mathrm{cms}$ birthmark and $45.7 \%$ have reported an increase in birthmark. Conclusions: We found birthmarks benign; they may grow with age but they do not need treatment unless there is concern either cosmetically or they have pain and discharge.

Key words: $\quad$ Melanocytic nevi, Salmon patches, Portwine stains, Cafe-au-lait macules, Mongolian spots, Sebaceous nevi, Congenital melanocytic nevi.

Article Citation: Asim SA, Maryum H, Shukar-ud-Din S, Jamalvi W, Aurangzeb M. Common birthmarks; to identify the frequency of in infants presenting to outpatient of tertiary care hospital. Professional Med J 2015;22(9):1208-1211. DOI: 10.17957/TPMJ/15.2842

\section{INTRODUCTION}

Birthmarks are usually evident at birth or thereafter. Mainly birthmarks were divided in two categories, vascular birthmarks; (often red, pink, purple) caused by abnormal blood vessels in or under skin. ${ }^{1}$ Pigmented birthmarks; (usually brown) caused by pigment cells, further divided into epidermal nevus and melanocytic nevi. It appears on all neonates almost with appearing on minor to major circumference of skin. ${ }^{2}$ Due to their benign nature of skinits not practiced routinely to consult dermatologist. ${ }^{3}$ As the thickness of infants skin is $40 \%$ to $60 \%$ of adult skin which predicts the weaker intercellular attachments. Therefore it is important for physician as well as for parents to understand the innocent transient skin lesions in infants and differentiate these birthmarks from serious conditions to only pigmented lesions like Mongolian spots(always disappear with time). ${ }^{4}$ The objective of this study was to screen the important pattern of birthmarks in Pakistan and to increase awareness among doctors about this common occurrence. However studies are very limited in our country. Hence it has been planned to highlight the prevalence of birthmarks in our setup.

\section{PATIENTS AND METHODOLOGY}

This cross sectional study was conducted in the Dermatology out patients department (OPD) of Dow University Hospital affiliated with Dow University of Health Sciences - Karachi, a tertiary care hospital from January -October 2014.Initially 123 patients were identified with birthmarks and interviewed and but only 100 were eligible to enroll in the study. Questionnaire was filled in an OPD of dermatology department after informed consent during 10 months. Physical examination was performed by dermatologist. Data collection included demographic variables as well as gender, 
type of birth, site and size of birthmark, color and pain bleeding etc. The result was analyzed on Statistical Software SPSS Version 17.Categorical variables like gender, type and size of birthmarks in the form of frequency and percentage.

\section{Results}

Out of 100 patients, $43 \%$ were males and $57 \%$ were females. In $69.6 \%$ patients, the birthmarks were noticed upon or soon after delivery, $28.3 \%$ patients were noticed within 1st year of life and $2.2 \%$ later in 5 year.

Pigmented birthmarks are more common in $65.2 \%$ patients, vascular birthmarks in $26.1 \%$ and $8.7 \%$ patients having both. Out of patients having pigmented birthmarks, $40 \%$ were epidermal nevi and $60 \%$ were melanocytic nevi. $4.2 \%$ had Salmon patches (stork mark), $4.3 \%$ had Portwine stains, $17.4 \%$ had Infantile hemangiomas, $13.0 \%$ had Epidermal nevi, 2.2\% had Sebaceous nevi, $8.7 \%$ had Congenital melanocytic nevi, $15.2 \%$ had Mongolian spots, $4.3 \%$ had Nevi of ota, $2.2 \%$ had Nevi of ita, $17.4 \%$ had Café-au-lait macules, 4.3\% had multiple birthmarks 1 (Salmon patches, Mongolian spots, Cafe-au-lait macules), 4.3\% had multiple birthmarks 2 (Epidermal nevi, Mongolian spots), and, $2.2 \%$ had multiple birthmarks 3 (Congenital melanocytic nevi, Mongolian spots, Nevi of oti).

Vascular birthmarks were noticed in $50 \%$ in males and $50 \%$ female, while pigmented birthmarks were noticed in $40 \%$ males and $60 \%$ females. The color of birthmarks were perceived as $45.7 \%$ were black or brown, $30.4 \%$ red, $6.5 \%$ white, $6.5 \%$ skincolored, $6.5 \%$ light-brown, $4.3 \%$ yellow/orange.

Out of total patients, $71.7 \%$ had no change of color during their life-span, $21.7 \%$ had become prominent or darkened, $4.3 \%$ had become lighter, and, $2.2 \%$ had changed color to red (became verrucous). From 32 patients $18.8 \%$ birthmarks were present in scalp, $21.9 \%$ on face, $12.6 \%$ on shoulder and neck, $12.5 \%$ on upper limb, $9.4 \%$ on lower limb, $18.8 \%$ on trunk, and, $9.4 \%$ on hip and lumber area. Out of 37 patients, size of birthmarks differ as $1-3 \mathrm{cms}$ in $37.8 \%, 4-6 \mathrm{cms}$ in $24.3 \%, 7-9 \mathrm{cms}$ in $8.1 \%, 10-12 \mathrm{cms}$ in $5.4 \%,>13$ $\mathrm{cms}$ in $24.3 \%$. From the total number of patients, $50.0 \%$ had no change of size in age, $45.7 \%$ had increase of size, and, $4.3 \%$ had decrease in size. Out of total patients, $4.3 \%$ birthmarks became hairy and $6.5 \%$ had pain, discharge or bleeding.

\section{Discussion}

Internationally various reports and studies have been published on birthmarks. The prevalence of birthmarks has been as high as $80 \%$ to $90 \%$ in Asians. ${ }^{7}$ An Indian study reported $62.2 \%$ birthmarks in newborns. ${ }^{8}$ No study has been conducted in Pakistan to identify the prevalence and recognition of commonly occurring birthmarks in infants. In our study the prevalence is $28.3 \%$ of those who had developed till one year of life. Female prevalence is higher with (57\%) as compared to male (43\%).

A survey of birthmarks on 500 Newborns: Clinical Observation in Two Northern Taiwan Medical Center Nurseries was conducted by I-Hsin Shih et al, vascular birthmarks was reported $27.8 \%$ while in our study it is $26.10 \%$ which is approximately similar. ${ }^{9}$ In 2010, A Retrospective review of patients identified only 27 patients with nevus birth marks reported commonly on forehead, glabella, upper eyelids and nape. More widespread involvement can be confused with port-wine stains (nervus flammeus) and other vascular birth marks. If we compare with present study we have identified $26.10 \%$ in the sample of 10 months in spite of only 100 samples.

Another study has been conducted in Finnish Hospitals taking account of 4346 infants to determine the frequency of birthmarks. Mostly birthmarks were placed on the forehead and neck.

Only $167 / 4346$ (3.8\%) had various vascular lesions and 21 (2.1\%) had other marks. We just identified $26.10 \%$ vascular in our study..$^{10}$ 


\begin{tabular}{|c|c|}
\hline Characteristics & Frequency (\%) \\
\hline \multicolumn{2}{|c|}{ Gender } \\
\hline Male & $43 \%$ \\
\hline Female & $57 \%$ \\
\hline \multicolumn{2}{|c|}{ Type of Birthmark } \\
\hline Vascular & $26.10 \%$ \\
\hline Naevus & $26.10 \%$ \\
\hline Dermal Menalocyte & $39.10 \%$ \\
\hline $\begin{array}{l}\text { Vascular \& Derma } \\
\text { melanocyte }\end{array}$ & $4.30 \%$ \\
\hline Naevus\& Dermal melanocyte & $4.30 \%$ \\
\hline \multicolumn{2}{|c|}{ Site of Birthmark } \\
\hline Arm & $4.30 \%$ \\
\hline Thigh & $4.30 \%$ \\
\hline Hip/Lumber area & $6.50 \%$ \\
\hline Face & $15.20 \%$ \\
\hline Scalp & $13.00 \%$ \\
\hline Chest & $4.30 \%$ \\
\hline Abdomen & $6.50 \%$ \\
\hline Forearm & $2.20 \%$ \\
\hline Neck & $4.30 \%$ \\
\hline Shoulder & $4.30 \%$ \\
\hline Hands/Feet & $4.30 \%$ \\
\hline \multicolumn{2}{|c|}{ Size of Birthmark } \\
\hline $1-3 \mathrm{~cm}$ & $30.40 \%$ \\
\hline $4-6 \mathrm{~cm}$ & $19.60 \%$ \\
\hline $7-9 \mathrm{~cm}$ & $6.50 \%$ \\
\hline $10-12 \mathrm{cms}$ & $4.30 \%$ \\
\hline$>16 \mathrm{cms}$ & $19.60 \%$ \\
\hline \multicolumn{2}{|c|}{ Colour of Birthmarks } \\
\hline Black/Dark Brown & $45.70 \%$ \\
\hline Red & $30.40 \%$ \\
\hline Yellow/Orange & $4.30 \%$ \\
\hline White & $6.50 \%$ \\
\hline Skin-coloured & $6.50 \%$ \\
\hline Light Brown & $6.50 \%$ \\
\hline \multicolumn{2}{|c|}{ Change in Size of Birthmark } \\
\hline Increased in Size & $45.70 \%$ \\
\hline Hairy & $4.30 \%$ \\
\hline Decreasedin Size & $4.30 \%$ \\
\hline \multicolumn{2}{|c|}{ Pain/Bleeding in Birthmark } \\
\hline Yes & $6.50 \%$ \\
\hline No & $93.50 \%$ \\
\hline $\begin{array}{l}\text { Table-I. Distribution } \\
\text { (site, size, co }\end{array}$ & $\begin{array}{l}\text { ent birthmarks } \\
\text { langes) }\end{array}$ \\
\hline
\end{tabular}

Most reported birthmark is dermal menalocyte nevi being $39.10 \%$. With $45.70 \%$ have brown color, around same numbers reported enlargement in size of birthmark. As most studies reported they don't need to be treated unless they have pain or bleeding, in our study $93.50 \%$ did not report pain or bleeding, exactly similar results were reported in different studies. ${ }^{11,12}$ However a more extensive and comprehensive study would probably be required in future to further determine the prevalence of birthmarks. Awareness can facilitate the patient's family and physician of better management and guidance.

\section{CONCLUSIONS}

Birthmarks are benign lesions; they may be present on any part of body at birth or develop soon afterwards as well. They may grow with age but they do not require active intervention unless there is concern either cosmetically or they have pain or bleeding or discharge. In majority of cases good counseling and observation is all that is required.

Copyright $\odot ~ 01$ June, 2015.

\section{REFERENCES}

1. Mulliken JB, Glowacki J. Hemangiomas and vascular malformations in infants and children: A classification based on endothelial characteristics. PlastReconstr Surg. 1982;6:412-22.

2. Lucky AW. Transient benign cutaneous lesions in the newborn.. In: Eichenfield LF, Frieden IJ, Esterly NB, editors. Neonatal dermatology. 2nd edition. Philadelphia: Saunders Elsevier; 2008. p. 85-97.

3. Boccardi D, Menni S, Ferraroni M, Stival G, Bernardo L, La Vecchia $C$, et al. Birthmarks and transient skin lesions in newborns and their relationship to maternal factors: a preliminary report from Northern Italy. Dermatology. 2007; 215:53-8.

4. Shih $\mathrm{I}-\mathrm{H}$, Lin J-Y, Chen $\mathrm{C}-\mathrm{H}$, Hong H-S. A birthmark survey in $\mathbf{5 0 0}$ newborns: clinical observation in two northern Taiwan medical center nurseries. Chang Gung Medical Journal. 2007;30(3):220-225.

5. FarhanaTahseenTaj Sameer Haveri ,Arun C. Inamadar. A Cross-Sectional Prospective Study of Cutaneous Lesions in Newborn. 2014; 2014: 360590.

6. Pack, G. T., \& Davis, J.Moles. New York State Journal of Medicine, 1956;56, 3498-3506. 
7. Prenatal stressors of human life affect fetal brain development. Developmental Medicine and Child Neurology, 36,826-832.

8. Pratt, A. G. Birthmarks in infants. AMA Archives of Dermatology and Syphilology, 1953;67, 302-305.

9. Shih Ih, Lin JY, Chen CH, HONG HS. A birthmark survey in $\mathbf{5 0 0}$ newborns: clinical observation in two northern Taiwan medical center nurseries. Chang Gun Med J. 2007 May-Jun;30(3):220-5.
10. Jacobs, A. H., \& Walton, R. G. The incidence of birthmarks in the neonate. Journal of Pediatrics, 1976; 58, 218-222.

11. Radin, D. I., \& Nelson, R. D. Evidence for consciousnessrelated anomalies in random physical systems. Foundations of Physics, 1989;19, 1499-1514.

12. Nanda A, Kaur S, Bhakoo ON, Dhall K. Survey of cutaneous lesions in Indian newborns. PediatrDermatol, 1989;6:39-42.

\section{5 \\ "The best revenge is massive success."}

\section{Frank Sinatra}

\begin{tabular}{|c|c|c|c|}
\hline \multicolumn{4}{|c|}{ AUTHORSHIP AND CONTRIBUTION DECLARATION } \\
\hline Sr. \# & Author-s Full Name & Contribution to the paper & Author $=$ s Signature \\
\hline 1 & Sadaf Ahmed Asim & $\begin{array}{l}\text { Concept, design, collection } \\
\text { of data, Analysis, Drafting } \\
\text { of article }\end{array}$ & \\
\hline 2 & & $\begin{array}{l}\text { Collection \& assembly of } \\
\text { data, Drafting }\end{array}$ & \\
\hline 3 & Shazia Shakor-ud-din & $\begin{array}{l}\text { Collection of data, Analysis } \\
\& \text { Interperation }\end{array}$ & \\
\hline 4 & Waseem Jamalvi & $\begin{array}{l}\text { Collection \& assembly of } \\
\text { data critical revision }\end{array}$ & \\
\hline 5 & Muhammad Aurangzed & Statistical analysis & \\
\hline
\end{tabular}

